\title{
Trade-through prohibitions and market quality
}

\author{
Terrence Hendershott ${ }^{\mathrm{a}, *}$, Charles M. Jones ${ }^{\mathrm{b}}$ \\ ${ }^{a}$ Haas School of Business, University of California, Berkeley, CA, USA \\ ${ }^{\mathrm{b}}$ Graduate School of Business, Columbia University, USA
}

\begin{abstract}
On September 4, 2002, the SEC implemented a de minimis exemption to the trade-through rule for three active ETFs, allowing markets to execute trades at prices up to three cents worse than those posted elsewhere. Relaxing the trade-through rule does not worsen ETF market quality. Effective and realized spreads are essentially unchanged or slightly smaller post-event, and prices become slightly more efficient. Part of the explanation is that, in these ETFs, tradethroughs are common, and their frequency changes little following the exemption. Thus, it is difficult to extrapolate from this regulatory experiment to draw broader policy conclusions about trade-through prohibitions.

(C) 2004 Elsevier B.V. All rights reserved.
\end{abstract}

\section{JEL Classification: G18; G28}

Keywords: Multi-market trading; Exchange competition; Securities regulation; National market system; Intermarket trading system (ITS)

\footnotetext{
${ }^{2}$ We gratefully acknowledge financial support from the New York Stock Exchange, but the comments and opinions expressed in this paper are the authors' and do not necessarily reflect those of the directors, members, or officers of the New York Stock Exchange, Inc. Hendershott gratefully acknowledges support from the National Science Foundation. Any errors or omissions are the responsibility of the authors alone.

*Corresponding author.

E-mail addresses: hender@haas.berkeley.edu (T. Hendershott), cj88@columbia.edu (C.M. Jones).
} 


\section{Introduction}

Financial market regulators and researchers are currently wrestling with a fundamental issue: how to facilitate competition between securities markets without destroying the liquidity externalities that arise when traders are able to come together in space and time. This balancing act underlies much of the U.S. regulatory system for multimarket trading. For example, other venues can trade stocks listed on the New York Stock Exchange (NYSE) or American Stock Exchange (AMEX), but most of these venues are linked together (by Congressional mandate). Among other things, the linkages are designed to enable investors to access the best price for a security, no matter where that price may be offered. Alongside these linkages is the so-called trade-through rule that prohibits venues from executing trades at prices worse than those posted elsewhere. This rule is controversial, in part because some market centers do not find the current linkages adequate. Via Regulation NMS, the U.S. Securities and Exchange Commission (SEC) is currently proposing to expand and modify trade-through prohibitions in all U.S. equity markets (SEC, 2004).

On September 4, 2002, the SEC relaxed the trade-through rule in the three most active exchange-traded funds (ETFs). This regulatory change allows us to examine the effect of trade-through prohibitions on market quality. Our results show that relaxing the trade-through rule in this case has little effect on market quality. ETF spreads are little changed, and if anything, there is evidence of a modest reduction in trading costs and a modest improvement in the efficiency of price discovery for these ETFs. When we look at the actual frequency of trade-throughs, we find that the relaxed rule has almost no impact on the incidence of trading through. This is somewhat surprising, but it explains the lack of effect on market quality. For whatever reason, when the trade-through rule is relaxed, trade-throughs change little, and overall market quality also changes little.

With rapid technological improvement and the consequent growth of electronic stock exchanges, competition between and regulation of trading venues are fundamental questions in market microstructure (see O'Hara (2004) for an overview). We know of no other work on the effects of trade-through rules, but research on competition between markets and on order routing and preferencing is related. ${ }^{1}$ The Nasdaq order handling rules (Barclay et al., 1999) and the cross-listing of equity options (de Fontnouvelle et al., 2003; Battalio et al., 2004) are excellent examples of how competition between venues benefits investors. ${ }^{2}$ Venues compete by posting quotes and also by arranging to receive order flow. Bessembinder (2003) and Chung et al. (2004), among others, examine order flow at venues not posting the best quotes. In studies designed to test causality, Battalio (1997) study NYSE stocks, and

\footnotetext{
${ }^{1}$ Preferencing is typically defined as execution by a venue not posting the best quotes and is often associated with payment for order flow. See Parlour and Rajan (2003) for a model with competition between venues, order routing, and preferencing/payment for order flow.

${ }^{2}$ Easley et al. (1996), Battalio et al. (1997), Bessembinder and Kaufman (1997), and Barclay et al. (2003) examine competition between venues and whether or not certain venues attract more or less informed traders. In addition, Barclay et al. (2003) and Bessembinder (2003) find that markets offering better prices are more likely to attract orders.
} 
Bloomfield and O'Hara (1998) use experiments, but both conclude that preferencing has little impact. If competition and best execution requirements (see Macey and O'Hara, 1997) can overcome potential agency problems between brokers and customers regarding order preferencing, the need for trade-through prohibitions is less clear. If indeed trade-through prohibitions are beneficial, then proper enforcement of them-something we find little evidence of - is required.

The paper proceeds as follows. Section 2 provides some details on ETFs, relevant linkages between markets, and the event at the heart of this study. Section 3 discusses the data and provides some descriptive statistics, Section 4 examines trading cost measures before and after the exemption takes effect, and Section 5 focuses on changes in the efficiency of prices. Section 6 tries to explain the result by looking at the incidence of trade-throughs before and after, while Section 7 concludes with some suggestions for improvements to the trade-through rule.

\section{Institutional background and empirical approach}

Before discussing the SEC's decision to relax the trade-through rule, some background on ETFs is useful. ETFs are registered investment companies under the Investment Company Act of 1940. Like open-end index funds, they hold portfolios designed to track a particular stock or bond index. However, they differ from openend index funds in two important ways. First, ETF shares can be traded continuously on major stock markets during the day. Second, at the end of every trading day, ETF shares can be created or redeemed by exchanging ETF shares (typically in multiples of 50,000 shares) for the appropriate number of shares of the underlying stocks. This ability to conduct arbitrage ensures that the ETF closely tracks its corresponding index. The first ETF, the S\&P 500 Trust Series I (SPY), listed on the American Stock Exchange (AMEX) in 1993. The success of SPY led to related products for the Nasdaq-100 (QQQ), Dow Jones Industrial Average (DIA), sector-specific indexes, and value and growth-oriented indexes. ${ }^{3}$ ETFs typically charge a management fee that is lower than that of a comparable open-end index mutual fund, though investors must also pay brokerage commissions to buy or sell ETFs.

The three most active ETFs-DIA, SPY, and QQQ - are all listed on the American Stock Exchange, but they trade many other places as well. They are traded at the NYSE, most of the regional stock exchanges, third market dealers such as Knight Securities, and also at most ECNs. In fact, by the middle of 2002, the leading venue for the major ETFs was the Island ECN.

The Intermarket Trading System (ITS) was developed in the late 1970s and early 1980s to link together electronically the NYSE, AMEX, regional stock exchanges,

\footnotetext{
${ }^{3}$ SPY, QQQ, and DIA are sponsored by an affiliate of the American Stock Exchange. Other major ETF sponsors include Merrill Lynch, which sponsors Holding Company Depository Receipts (HOLDRS), and Barclays Global Investors, which markets and manages iShares.
} 
off-exchange dealers, and other trading venues. ${ }^{4}$ Its central purpose is to create a national market in NYSE and AMEX stocks, so that market participants can see and access the best bid and offer prices across all venues. A key requirement is that ITS members cannot trade through a price quoted on another venue. There are exceptions for large block trades and in certain other situations. In most cases, however, if a better price is offered in another market and the home market is unable to match this price, the order must be sent to the other market via ITS. This is true even if the quoted size in the other market is smaller than the order, as long as this quoted size is more than 100 shares (see the discussion in Hasbrouck et al., 1993). The idea is that at least part of the order can and should be executed at the better price in the other market.

In practice, the market on the receiving end of an ITS order has up to 30 seconds to respond. In effect, this means that the receiving market potentially has a 30 second option to execute or decline the ITS order. Prices on the largest ETFs move rapidly, in part because arbitrage links ETF prices to prices on electronically traded index futures in Chicago. This means that some ETF market participants have a strong demand for immediacy. In addition, the securities have such narrow spreads that the 30 -second option is potentially valuable to an ETF market-maker. This value to the market-maker is a cost to the investor whose order is sent over ITS. Thus, in the ETF case especially, ITS and the trade-through rule have the potential to increase investor trading costs, a standard measure of market quality, as well as reduce the speed and certainty of order execution.

In an effort to address some of these concerns, the SEC issued an exemption to the trade-through rule on August 28, 2002, effective September 4, 2002. The so-called de minimis exemption applies only to the three most active ETFs (DIA, QQQ, and SPY), and it allows firms and trading venues to trade through the consolidated quote's national best bid-offer (NBBO) by at most three cents. The exemption is explicitly temporary and is designed as a stopgap measure while the SEC evaluates the trade-through rule, ITS, and linkages between markets more generally. However, the 3-cent exemption remains in effect as of the date of this writing.

We examine the effect of the de minimis exemption on market quality in the affected ETFs. Using standard event study methodology, we look at trading costs and the efficiency of prices during the period just before and just after the exemption took effect. We measure trading costs using effective spreads and realized spreads. Short-horizon return autocorrelations are used as simple gauges of the efficiency of price discovery. In addition to changes in overall market quality, we analyze market quality on each identifiable trading venue, in an effort to determine if the 3-cent rule has a differential effect across venues. We also control for confounding effects, including changes in price level, volatility, and market-wide liquidity.

The pre-event period covers the interval from August 16, 2002 to September 3, 2002, the last trading day before the exemption went into effect. The post-event period covers the interval from September 4, 2002 through September 20, 2002.

\footnotetext{
${ }^{4}$ Historically, Nasdaq has not prohibited trade-throughs. Regulation NMS would prohibit tradethroughs on Nasdaq.
} 
The next trading day, September 23, 2002, the SEC required that Island come into compliance with the display requirements of Regulation ATS. Island decided to do so by going dark. It stopped displaying its limit order book completely in the affected ETFs, which included DIA, QQQ, and SPY. This reduction in transparency, and Island's loss of market share, caused a dramatic change in market quality for these ETFs, as discussed in Hendershott and Jones (2004). To avoid this confounding event, we end our sample before Island goes dark.

\section{Data and descriptive statistics}

Our data consist of all the trades and quotes for the three ETFs that were covered by the three cent trade-through exemption-DIA, QQQ, and SPY-during normal trading hours from 9:30 a.m. to 4:00 p.m. The sample period extends from August 16, 2002 to September 20, 2002 and covers 25 trading days, 12 in the pre-event period and 13 in the post-event period. ${ }^{5}$ Trade and quote data are gathered from the NYSE's TAQ database and Island's ITCH data. The TAQ data identify several different trading and quoting venues, including the NYSE, AMEX, Chicago Board Options Exchange (CBOE), Boston, Cincinnati, Midwest, Pacific, and Philadelphia exchanges, as well as Nasdaq's Computer Assisted Execution System (CAES), which is often referred to as the 3rd market. Market-makers such as Knight Securities and ECNs such as Instinet print their trades on CAES. We discard Philadelphia and CBOE trades and quotes because their combined market share in these ETFs is less than 1\%. The Pacific exchange trades using Archipelago's ECN technology, so it is essentially an ECN. The TAQ data do not distinguish among third-market participants, so all third-market trades other than those matched to Island trades (see below) are treated as a single venue. ${ }^{6}$

During this period in these ETFs, the Island ECN prints some of its trades on CAES and some on the Cincinnati. We are able to identify these trades in TAQ using Island's ITCH data feed. The ITCH data from Island provide a record of each trade and each change to the Island limit order book. These data are time-stamped to the nearest millisecond and are identical to those supplied in real time to Island subscribers. To identify Island trades in TAQ we look for ITCH trades that exactly match Cincinnati and 3rd market TAQ trades. Due to timing delays in communicating across systems, the trade time in TAQ is usually a couple of seconds later than the ITCH trade time. Thus, we first match trades on price and size using a two-second time lag. For the remaining unmatched ITCH trades, we look for matches that print in TAQ three seconds later, and we repeat this process using lags of 1,4 , and then 5 seconds. This approach identifies 99 percent of the Island trades in TAQ.

\footnotetext{
${ }^{5}$ August 16, 2002 was chosen as the beginning date because ETF trades on Archipelago are reported through the Pacific Stock Exchange starting then.

${ }^{6}$ Rule $11 \mathrm{Ac} 1-5$ reports show that about $2 / 3$ of non-Island 3rd-market trading is Instinet, so we refer to this group as Instinet-3rd Market.
} 
Many measures of market quality require a quote midpoint. For example, an effective spread is typically defined relative to the quote midpoint prevailing at the time of the trade. In the case of these ETFs, there is more than one way to calculate a quote midpoint. The standard approach is to use the NBBO from TAQ. However, this would exclude Island limit orders, since Island does not participate in the consolidated quote system during this period. Hendershott and Jones (2004) find that the majority of ETF price discovery takes place on Island, and thus it might be important to include Island quotes to get an accurate quote midpoint. Island's BBO can be calculated using the ITCH data (see Hendershott and Jones, 2004, for details), but merging this with the TAQ NBBO is a challenge because of the uncertain time lag between ITCH time stamps and TAQ time stamps. All measures in the paper have been calculated including and excluding Island quotes, with lags from zero to two seconds. The qualitative results do not depend on how the quote midpoint is measured, so we report most of the results based only on the TAQ NBBO. ${ }^{7}$

Using the Lee and Ready (1991) algorithm, non-Island trades are classified as buyer-initiated if the trade price is greater than the contemporaneous quote midpoint and seller-initiated if the trade price is less than the quote midpoint. Trades executed at the midpoint are classified with the tick rule: midpoint trades on an up-tick are classified as buyer-initiated, and midpoint trades on a downtick are classified as seller-initiated. For Island trades, the ITCH data indicate whether the marketable order is a buy or sell, and we use this to sign Island trades. Using the ITCH buy-sell indicator only affects Island trades, and its primary benefit is to increase the precision of the estimates of Island's effective and realized spreads. The qualitative results are unchanged if we use the Lee and Ready (1991) algorithm for Island trades as well. ${ }^{8}$

Table 1 describes the daily trading activity in these ETFs before and after the de minimis exemption goes into effect. All three ETFs are very active, averaging almost two trades per second for QQQ and a little over one trade per second for SPY. Island is the dominant venue in terms of share volume for DIA and QQQ. For SPY, Island executes the majority of trades, but its smaller trade size results in it having 21 to 22 percent of the share volume. Both AMEX and Instinet-3rd market have greater share volume in SPY. The event does not seem to affect trading volume or the market share of various venues. This is perhaps not surprising. If the trade-through exemption has an effect on competition across venues, it might take more than a few weeks to materialize. To take a hypothetical example, the increased ability to trade through might enable a venue to increase its payment for order flow, but it might take a while before this venue is able to attract additional order flow with its increased rebates.

\footnotetext{
${ }^{7}$ In the reported results, we retain all quotes, including those that lock or cross the NBBO (the best bid equals or exceeds the best offer, respectively). The results are not sensitive to including these quotes.

${ }^{8}$ In our sample, Lee-Ready signs Island trades correctly only about $60 \%$ of the time-about $70 \%$ for trades executing against visible orders and about $50 \%$ for trades against hidden orders.
} 
Table 1

Descriptive statistics

TAQ and ITCH data for the three exchange-traded funds-DIA, QQQ, and SPY. The pre-period is August 16, 2002 to September 3, 2002 and the post-period is September 4, 2002 to September 20, 2002. Descriptive statistics are calculated for each ETF each day and then averaged across days.

\begin{tabular}{|c|c|c|c|c|c|c|}
\hline \multirow[t]{2}{*}{ Average daily } & \multicolumn{2}{|l|}{ DIA } & \multicolumn{2}{|l|}{ QQQ } & \multicolumn{2}{|l|}{ SPY } \\
\hline & Pre & Post & Pre & Post & Pre & Post \\
\hline Volume (M shares) & 9.12 & 9.28 & 81.95 & 73.26 & 33.34 & 37.41 \\
\hline Volume (000 trades) & 17.52 & 16.32 & 44.41 & 42.61 & 27.13 & 27.05 \\
\hline Price & 88.16 & 83.47 & 24.59 & 22.66 & 93.70 & 88.93 \\
\hline Avg trade size (shs) & 521 & 569 & 1845 & 1719 & 1229 & 1383 \\
\hline \multicolumn{7}{|l|}{ Market share (shares) } \\
\hline AMEX & 0.24 & 0.26 & 0.19 & 0.17 & 0.28 & 0.26 \\
\hline Boston & 0.02 & 0.02 & 0.04 & 0.04 & 0.04 & 0.03 \\
\hline Cincinnati & 0.02 & 0.02 & 0.02 & 0.02 & 0.02 & 0.02 \\
\hline Island & 0.37 & 0.35 & 0.33 & 0.38 & 0.22 & 0.21 \\
\hline Midwest & 0.05 & 0.04 & 0.04 & 0.04 & 0.02 & 0.02 \\
\hline NYSE & 0.05 & 0.05 & 0.07 & 0.07 & 0.08 & 0.07 \\
\hline ARCA-Pacific & 0.03 & 0.04 & 0.01 & 0.02 & 0.02 & 0.02 \\
\hline Instinet-3rd market & 0.21 & 0.22 & 0.28 & 0.24 & 0.33 & 0.37 \\
\hline \multicolumn{7}{|l|}{ Market share (trades) } \\
\hline AMEX & 0.08 & 0.09 & 0.06 & 0.06 & 0.13 & 0.13 \\
\hline Boston & 0.03 & 0.02 & 0.07 & 0.05 & 0.08 & 0.06 \\
\hline Cincinnati & 0.02 & 0.02 & 0.01 & 0.01 & 0.01 & 0.01 \\
\hline Island & 0.61 & 0.60 & 0.57 & 0.60 & 0.55 & 0.56 \\
\hline Midwest & 0.05 & 0.03 & 0.06 & 0.05 & 0.03 & 0.03 \\
\hline NYSE & 0.02 & 0.02 & 0.04 & 0.04 & 0.03 & 0.03 \\
\hline ARCA-Pacific & 0.05 & 0.05 & 0.03 & 0.02 & 0.04 & 0.04 \\
\hline Instinet-3rd market & 0.15 & 0.17 & 0.15 & 0.14 & 0.13 & 0.14 \\
\hline
\end{tabular}

Island's large market share is relevant because it remains outside ITS throughout the whole sample, so it is largely unaffected by the rule change. Broker-dealers who route orders to Island are responsible for ensuring best execution, and in principle they would be subject to the trade-through prohibitions. However, most Island orders are routed there by the account holder rather than an intermediary, rendering moot the usual agency concerns. Thus, we might not expect to find any effect on Island. Given Island's substantial market share at the time, this might bias the overall market quality results toward showing no change. In contrast, we would probably expect the biggest effects at venues where brokers internalize or pay for order flow, particularly the non-automated regional exchanges.

\section{The effect of the de minimis exemption on trading costs}

Our goal in this section is to measure changes in trading costs as an important component of market quality. However, it is important to remember that total 
trading costs include implicit, explicit, and opportunity costs. Because we do not have order submission data or a complete breakdown of commissions, we focus on the implicit trading costs as indicated by measures of the spread. We focus on effective spreads and realized spreads.

Effective spreads are perhaps the most common measure of trading cost. For all markets except Island, effective half-spreads are defined in the usual way as the absolute difference between the transaction price and the midpoint of the contemporaneous $\mathrm{NBBO}$, calculated using all valid quotes available in TAQ. As discussed in the previous section, the ITCH data reveal whether a trade was initiated by the buyer or the seller, and we use this indicator to obtain a more accurate measure of the effective spread. For example, if the trade is initiated by the seller, then the effective spread is the prevailing quote midpoint minus the execution price. In contrast to the usual approach, the effective spread can potentially be negative using this method.

Realized spreads - the difference between the transaction price and the quote midpoint five minutes after the trade, signed by the direction of the trade - provide an ex post measure of trading cost to the demander of liquidity and an ex post measure of gross profitability for the provider of liquidity. Realized spreads are often used as a measure of a market's competitiveness. For all markets except Island, trades above the midpoint are considered buys, and trades below the midpoint are considered sells. For trades on Island, the ITCH data reveal whether a trade was buyer or seller-initiated.

\subsection{Consolidated effective spreads}

Table 2 displays average effective half-spreads by ETF, venue, and trade size over the sample period. All trading cost measures in the paper are calculated as shareweighted averages over a trading day, and the reported figures are the average across trading days. Throughout the paper, we calculate standard errors and conduct statistical tests based on the daily time series, assuming independence across trading days.

Overall half-spreads are modest, averaging around four cents for DIA and SPY on a share-weighted basis, and a bit less than three cents for QQQ. This corresponds to about 5 basis points for DIA and SPY, and about 10 basis points for QQQ. There is no evidence that market quality worsens when the trade-through rule is relaxed. In fact, overall effective spreads actually fall for all three ETFs, and the fall is statistically significant for DIA and QQQ. For example, average QQQ effective halfspreads are 2.91 cents pre-event and 2.48 cents afterward. DIA half-spreads fall from 4.21 to 3.71 cents; SPY half-spreads decline modestly from 4.04 to 3.93 cents.

The ITS trade-through rules generally do not apply to block trades, which are defined by most ITS participants as trades of 10,000 shares or more. To focus on the trades that are affected by the trade-through exemption, we partition trades into three sizes. Small trades are 1,000 shares or fewer, medium trades are 1,001 to 9,999 shares, and large trades are at least 10,000 shares. The affected trades are in the small and medium category, and the results are similar to the overall results. Effective 
Table 2

Effective half-spreads

The distance between the transaction price and the prevailing quote midpoint in cents for each ETF each day (averaged on a per-share basis) and then averaged across days, with standard errors in parentheses. The pre-period is August 16, 2002 to September 3, 2002 and the post-period is September 4, 2002 to September 20, 2002.

\begin{tabular}{|c|c|c|c|c|c|c|}
\hline \multirow[t]{2}{*}{ Trade size } & \multicolumn{2}{|l|}{ DIA } & \multicolumn{2}{|l|}{ QQQ } & \multicolumn{2}{|l|}{ SPY } \\
\hline & Pre & Post & Pre & Post & Pre & Post \\
\hline Small & 3.32 & $2.91 *$ & 2.58 & 2.31 & 3.11 & 2.92 \\
\hline (100 to 1,000 shares) & $(0.11)$ & $(0.09)$ & $(0.13)$ & $(0.20)$ & $(0.19)$ & $(0.24)$ \\
\hline Medium & 4.42 & $3.90^{*}$ & 2.60 & 2.34 & 3.56 & 3.39 \\
\hline (1,001 to 9,999 shares) & $(0.13)$ & $(0.11)$ & $(0.14)$ & $(0.19)$ & $(0.19)$ & $(0.32)$ \\
\hline Large & 5.96 & $4.92 *$ & 3.31 & $2.70 *$ & 4.75 & 4.62 \\
\hline$(10,000$ shares or more $)$ & $(0.41)$ & $(0.18)$ & $(0.26)$ & $(0.15)$ & $(0.30)$ & $(0.42)$ \\
\hline \multirow[t]{2}{*}{ Overall } & 4.21 & $3.71 *$ & 2.91 & $2.48 *$ & 4.04 & 3.93 \\
\hline & $(0.14)$ & $(0.10)$ & $(0.16)$ & $(0.17)$ & $(0.24)$ & $(0.34)$ \\
\hline
\end{tabular}

An asterisk $(*)$ represents a statistically significant difference between the pre and post period at the 0.05 level.

spreads decline for every size bucket and every ETF, though most of the declines are statistically insignificant. For DIA, both small and medium trades become significantly cheaper, though the effect is modest. Small trade spreads decline from 3.32 cents to 2.91 cents, and spreads on medium trades fall from 4.42 to 3.90 cents.

\subsection{Effective spreads across venues}

The de minimis exemption does not seem to be associated with a decline in overall ETF market quality. However, it is possible that market-makers at some market centers could use the exemption as an opportunity to trade through other markets, giving customers worse executions. If this were to happen anywhere, we might expect it at regional exchanges that pay for order flow or allow broker-dealers to effectively internalize. To investigate this, we look at effective spreads for each venue that prints trades in TAQ. Though we provide overall effective spreads and effective spreads for each trade size bucket, we focus on small trades of 1,000 shares or fewer, where this potential agency problem might be most severe. The results are in Table 3 , and they indicate that this hypothesis is completely unsupported by the data. There is no evidence that any venue uses the de minimis exemption to provide worse execution to customers. In fact, effective spreads actually fall significantly at a number of venues for DIA and SPY. For QQQ, effective spreads fall at all of the venues, but none of the changes are statistically distinguishable from zero. For SPY, there are small spread increases at Boston (3.37 to 3.48 cents), the Midwest (3.27 to 3.31 cents), and on the 3rd market (3.24 to 3.42 cents), but these are tiny and are indistinguishable from statistical noise. So far, the three-cent rule appears to be a non-event in terms of harming market quality. 
Table 3

Effective half-spreads by venue

In cents, with standard errors immediately beneath. See Table 2 for additional calculation details.

\begin{tabular}{|c|c|c|c|c|c|c|c|c|c|c|c|c|c|c|c|c|}
\hline \multirow[t]{2}{*}{ Trade size } & \multicolumn{2}{|c|}{ AMEX } & \multicolumn{2}{|c|}{ Boston } & \multicolumn{2}{|c|}{ Cinn } & \multicolumn{2}{|c|}{ Island } & \multicolumn{2}{|c|}{ Midwest } & \multicolumn{2}{|c|}{ NYSE } & \multicolumn{2}{|c|}{ ARCA-P } & \multicolumn{2}{|c|}{ Instinet-3rd } \\
\hline & Pre & Post & Pre & Post & Pre & Post & Pre & Post & Pre & Post & Pre & Post & Pre & Post & Pre & Post \\
\hline \multicolumn{17}{|l|}{$D I A$} \\
\hline \multirow[t]{2}{*}{ Small } & 3.98 & $3.73^{*}$ & 4.80 & 4.57 & 2.96 & 2.79 & 3.06 & $2.66^{*}$ & 4.11 & $3.35^{*}$ & 4.01 & $3.68^{*}$ & 2.39 & $2.11^{*}$ & 3.47 & $3.03 *$ \\
\hline & 0.13 & 0.11 & 0.21 & 0.27 & 0.21 & 0.19 & 0.10 & 0.10 & 0.18 & 0.17 & 0.15 & 0.13 & 0.10 & 0.06 & 0.14 & 0.12 \\
\hline \multirow[t]{2}{*}{ Medium } & 4.77 & $4.38^{*}$ & 6.29 & 5.79 & 5.25 & 5.48 & 3.04 & $2.71^{*}$ & 4.91 & $3.93^{*}$ & 4.50 & $4.00^{*}$ & 2.75 & 2.78 & 5.53 & $4.11^{*}$ \\
\hline & 0.16 & 0.19 & 0.52 & 0.49 & 0.43 & 0.46 & 0.15 & 0.13 & 0.41 & 0.18 & 0.20 & 0.19 & 0.40 & 0.50 & 0.35 & 0.22 \\
\hline \multirow[t]{2}{*}{ Large } & 6.72 & $5.03^{*}$ & 5.25 & $2.50^{*}$ & 7.89 & $4.08^{*}$ & 2.27 & 2.28 & 8.18 & 5.09 & 6.44 & $4.77^{*}$ & 1.77 & 1.67 & 5.85 & 5.35 \\
\hline & 0.76 & 0.26 & 0.25 & 0.00 & 1.72 & 0.91 & 0.21 & 0.26 & 3.73 & 1.31 & 0.60 & 0.39 & 0.57 & 0.37 & 0.35 & 0.34 \\
\hline \multirow[t]{2}{*}{ Overall } & 5.32 & $4.48^{*}$ & 5.11 & 4.72 & 4.21 & 3.91 & 3.03 & $2.66^{*}$ & 4.35 & $3.63^{*}$ & 4.95 & $4.29 *$ & 2.41 & 2.21 & 4.96 & $4.41 *$ \\
\hline & 0.33 & 0.17 & 0.26 & 0.27 & 0.43 & 0.44 & 0.11 & 0.09 & 0.25 & 0.17 & 0.21 & 0.20 & 0.12 & 0.11 & 0.19 & 0.21 \\
\hline \multicolumn{17}{|l|}{$Q Q Q$} \\
\hline \multirow[t]{2}{*}{ Small } & 2.51 & 2.32 & 2.45 & 2.15 & 1.72 & 1.67 & 2.64 & 2.33 & 2.56 & 2.36 & 2.59 & 2.56 & 1.79 & 1.64 & 2.70 & 2.44 \\
\hline & 0.16 & 0.25 & 0.14 & 0.18 & 0.08 & 0.17 & 0.13 & 0.20 & 0.14 & 0.20 & 0.21 & 0.23 & 0.15 & 0.18 & 0.15 & 0.25 \\
\hline \multirow[t]{2}{*}{ Medium } & 2.58 & 2.33 & 2.49 & 2.36 & 1.92 & 2.32 & 2.58 & 2.26 & 3.00 & 2.70 & 2.43 & 2.62 & 2.08 & 1.67 & 2.76 & 2.50 \\
\hline & 0.17 & 0.20 & 0.16 & 0.21 & 0.29 & 0.41 & 0.15 & 0.18 & 0.18 & 0.20 & 0.15 & 0.26 & 0.43 & 0.23 & 0.19 & 0.24 \\
\hline \multirow[t]{2}{*}{ Large } & 2.70 & 2.66 & 3.10 & 2.20 & 5.40 & $2.61^{*}$ & 2.50 & 2.37 & 2.64 & $2.08^{*}$ & 3.48 & $2.75^{*}$ & 1.34 & 1.78 & 3.47 & $2.74^{*}$ \\
\hline & 0.27 & 0.43 & 1.02 & 0.28 & 1.44 & 0.25 & 0.27 & 0.29 & 0.32 & 0.21 & 0.26 & 0.20 & 0.27 & 0.70 & 0.40 & 0.23 \\
\hline \multirow[t]{2}{*}{ Overall } & 2.67 & 2.54 & 2.55 & 2.28 & 4.50 & $2.54^{*}$ & 2.59 & 2.29 & 2.78 & 2.52 & 3.12 & $2.72 *$ & 1.87 & 1.68 & 3.31 & $2.67 *$ \\
\hline & 0.21 & 0.30 & 0.16 & 0.19 & 0.99 & 0.19 & 0.14 & 0.19 & 0.16 & 0.18 & 0.19 & 0.20 & 0.20 & 0.17 & 0.31 & 0.20 \\
\hline \multicolumn{17}{|l|}{$S P Y$} \\
\hline \multirow[t]{2}{*}{ Small } & 3.17 & $2.88^{*}$ & 3.37 & 3.48 & 1.83 & $1.56^{*}$ & 3.09 & 2.77 & 3.27 & 3.31 & 3.22 & 2.85 & 2.11 & 2.06 & 3.24 & 3.42 \\
\hline & 0.16 & 0.09 & 0.17 & 0.37 & 0.14 & 0.10 & 0.20 & 0.17 & 0.23 & 0.44 & 0.29 & 0.12 & 0.08 & 0.10 & 0.22 & 0.67 \\
\hline \multirow[t]{2}{*}{ Medium } & 3.62 & $3.26^{*}$ & 3.81 & 3.76 & 2.76 & 2.47 & 3.47 & 3.32 & 3.44 & 3.60 & 3.88 & 3.38 & 2.41 & 2.24 & 3.59 & 3.80 \\
\hline & 0.19 & 0.10 & 0.19 & 0.37 & 0.64 & 0.63 & 0.22 & 0.33 & 0.18 & 0.39 & 0.40 & 0.13 & 0.30 & 0.17 & 0.22 & 0.87 \\
\hline \multirow[t]{2}{*}{ Large } & 4.27 & 4.37 & 5.87 & 9.11 & 5.57 & 4.96 & 3.75 & 5.13 & 5.84 & 3.93 & 3.96 & 3.55 & 1.62 & $0.50^{*}$ & 5.16 & 4.99 \\
\hline & 0.41 & 0.49 & 1.44 & 3.71 & 0.90 & 0.61 & 0.81 & 1.70 & 1.15 & 1.08 & 0.45 & 0.29 & 0.16 & 0.50 & 0.35 & 0.46 \\
\hline \multirow[t]{2}{*}{ Overall } & 3.93 & 3.80 & 3.61 & 3.73 & 5.00 & 4.56 & 3.21 & 3.02 & 3.59 & 3.65 & 3.92 & 3.48 & 2.18 & 2.13 & 4.81 & 4.76 \\
\hline & 0.30 & 0.28 & 0.17 & 0.43 & 0.73 & 0.47 & 0.20 & 0.26 & 0.21 & 0.41 & 0.40 & 0.24 & 0.12 & 0.11 & 0.31 & 0.52 \\
\hline
\end{tabular}

An asterisk $(*)$ represents a statistically significant difference between the pre- and post-period at the 0.05 level.

\subsection{Realized spreads}

The de minimis exemption does not seem to be associated with an increase in effective spreads. In fact, the previous subsection provides some weak evidence that effective spreads actually narrow under the 3-cent trade-through rule. We next explore ex post trading costs using the realized spread. A simple spread decomposition indicates that the realized spread after five minutes, a measure of the gross profit to supplying liquidity, equals gross revenues less costs. The effective spread is the gross revenue, and the cost of supplying liquidity is the price impact of the trade, defined here as the amount by which the quote midpoint moves against the liquidity supplier in the five minutes following the trade. Thus, if effective spreads 
Table 4

Realized half-spreads

Gross trading profits for liquidity suppliers, measured using the quote midpoint five minutes after the trade, in cents for each ETF each day (averaged on a per-share basis) and then averaged across days, with standard errors in parentheses. The pre period is August 16, 2002 to September 3, 2002 and the post period is September 4, 2002 to September 20, 2002.

\begin{tabular}{|c|c|c|c|c|c|c|}
\hline \multirow[t]{2}{*}{ Trade size } & \multicolumn{2}{|l|}{ DIA } & \multicolumn{2}{|l|}{ QQQ } & \multicolumn{2}{|l|}{ SPY } \\
\hline & Pre & Post & Pre & Post & Pre & Post \\
\hline Small & 0.96 & 0.82 & 0.60 & $0.41 *$ & 0.77 & $0.57 *$ \\
\hline (100 to 1,000 shares) & $(0.08)$ & $(0.07)$ & $(0.05)$ & $(0.05)$ & $(0.10)$ & $(0.07)$ \\
\hline Medium & 3.20 & $2.62 *$ & 0.64 & $0.52 *$ & 1.70 & 1.43 \\
\hline (1,001 to 9,999 shares) & $(0.24)$ & $(0.25)$ & $(0.05)$ & $(0.04)$ & $(0.12)$ & $(0.17)$ \\
\hline Large & 5.36 & $4.00^{*}$ & 1.26 & 1.26 & 3.23 & 3.87 \\
\hline$(10,000$ shares or more $)$ & $(0.85)$ & $(0.47)$ & $(0.36)$ & $(0.49)$ & $(0.46)$ & $(0.38)$ \\
\hline \multirow[t]{2}{*}{ Overall } & 2.44 & 2.09 & 0.91 & 0.83 & 2.20 & 2.53 \\
\hline & $(0.22)$ & $(0.16)$ & $(0.16)$ & $(0.17)$ & $(0.25)$ & $(0.24)$ \\
\hline
\end{tabular}

An asterisk $(*)$ represents a statistically significant difference between the pre- and post-period at the 0.05 level.

narrow, either liquidity providers are earning smaller profits per trade, or the trades themselves are associated with smaller price impacts. To distinguish between these two explanations, we measure five-minute realized spreads overall and by venue. As before, we partition by trade size, since only trades of less than 10,000 shares are subject to the trade-through rule. We continue to focus on the smallest trades of at most 1,000 shares, though the results for medium-sized trades are similar.

Realized spreads fall modestly for these small trades. SPY liquidity suppliers, for example, earn an average of 0.77 cents per share before the trade-through prohibition is relaxed, and they earn 0.57 cents per share afterward. There is a similar decline for DIA and QQQ liquidity suppliers, though the fall in DIA realized spreads is not quite significant at the $5 \%$ level (Table 4). These indicate that the market for supplying liquidity to smaller orders actually becomes slightly more competitive with the de minimis exemption, though the effects are economically modest. Again, there is no evidence that the trade-through exemption hurts ETF market quality.

Next, we investigate the possibility that some market centers could use the exemption as an opportunity to trade through other markets, giving customers worse executions. If this were happening, we would expect to see an increase in realized spreads on that venue. We look at realized spreads for each identifiable venue in TAQ, and we partition by trade size to focus on the profits from interacting with small orders. There is no systematic evidence of this behavior in Table 5. Realized spreads decline at most venues, though the changes are mostly indistinguishable from zero. For small orders of 1,000 shares or less, there is an increase in realized spreads on Cincinnati in DIA, but these findings do not extend to the other ETFs, 
Table 5

Realized half-spreads by venue

In cents, with standard errors immediately beneath. See Table 4 for additional calculation details.

\begin{tabular}{|c|c|c|c|c|c|c|c|c|c|c|c|c|c|c|c|c|}
\hline \multirow[t]{2}{*}{ Trade size } & \multicolumn{2}{|c|}{ AMEX } & \multicolumn{2}{|c|}{ Boston } & \multicolumn{2}{|l|}{ Cinn } & \multicolumn{2}{|l|}{ Island } & \multicolumn{2}{|c|}{ Midwest } & \multicolumn{2}{|c|}{ NYSE } & \multicolumn{2}{|c|}{ ARCA-P } & \multicolumn{2}{|c|}{ Instinet-3rd } \\
\hline & Pre & Post & Pre & Post & Pre & Post & Pre & Post & Pre & Post & Pre & Post & Pre & Post & Pre & Post \\
\hline \multicolumn{17}{|l|}{$D I A$} \\
\hline \multirow[t]{2}{*}{ Small } & 2.89 & 2.59 & 3.07 & 3.46 & 0.75 & $1.67^{*}$ & 0.13 & $-0.12 *$ & 3.07 & 3.13 & 3.05 & 3.00 & 0.98 & 0.82 & 1.31 & 1.26 \\
\hline & 0.19 & 0.18 & 0.32 & 0.44 & 0.33 & 0.49 & 0.10 & 0.06 & 0.29 & 0.39 & 0.48 & 0.41 & 0.36 & 0.45 & 0.18 & 0.12 \\
\hline \multirow[t]{2}{*}{ Medium } & 4.00 & 3.81 & 4.19 & 4.16 & 2.93 & $7.90 *$ & 1.21 & $0.27 *$ & 3.59 & 2.90 & 3.36 & 2.52 & -0.24 & -0.08 & 3.97 & $2.09 *$ \\
\hline & 0.29 & 0.39 & 1.18 & 1.41 & 2.21 & 1.78 & 0.31 & 0.50 & 0.66 & 0.88 & 0.72 & 0.51 & 1.93 & 1.07 & 0.88 & 0.54 \\
\hline \multirow[t]{2}{*}{ Large } & 4.04 & 2.63 & 3.75 & -1.50 & 6.99 & 2.03 & -4.41 & -0.09 & 15.61 & $3.02 *$ & 5.02 & 2.02 & -0.92 & 5.70 & 7.00 & 5.94 \\
\hline & 0.95 & 0.87 & 4.25 & 0.00 & 4.05 & 3.01 & 2.34 & 2.29 & 8.27 & 2.49 & 1.82 & 1.49 & 4.75 & 3.85 & 1.75 & 0.86 \\
\hline \multirow[t]{2}{*}{ Overall } & 3.81 & $2.92 *$ & 3.28 & 3.34 & 1.74 & 3.04 & 0.14 & 0.04 & 3.45 & 3.10 & 3.77 & 2.64 & 0.79 & 1.12 & 4.61 & 3.91 \\
\hline & 0.32 & 0.37 & 0.36 & 0.44 & 1.26 & 1.33 & 0.10 & 0.14 & 0.72 & 0.38 & 0.86 & 0.66 & 0.48 & 0.51 & 1.07 & 0.46 \\
\hline \multicolumn{17}{|l|}{$Q Q Q$} \\
\hline \multirow[t]{2}{*}{ Small } & 1.20 & 1.11 & 1.65 & $1.31^{*}$ & 0.92 & 0.81 & 0.02 & 0.02 & 1.62 & 1.32 & 1.25 & 1.10 & 0.94 & $0.43 *$ & 1.12 & $0.67 *$ \\
\hline & 0.13 & 0.12 & 0.16 & 0.13 & 0.43 & 0.15 & 0.05 & 0.03 & 0.16 & 0.17 & 0.13 & 0.12 & 0.13 & 0.15 & 0.07 & 0.09 \\
\hline \multirow[t]{2}{*}{ Medium } & 1.32 & 1.47 & 1.73 & 1.53 & 1.33 & 0.60 * & 0.02 & -0.08 & 1.95 & 1.77 & 1.22 & 1.41 & 0.63 & 1.01 & 1.19 & $0.84 *$ \\
\hline & 0.14 & 0.10 & 0.20 & 0.16 & 0.29 & 0.28 & 0.06 & 0.04 & 0.20 & 0.13 & 0.19 & 0.17 & 0.37 & 0.29 & 0.16 & 0.18 \\
\hline \multirow[t]{2}{*}{ Large } & 1.19 & 1.67 & 1.37 & $2.91 *$ & 1.54 & 1.87 & -0.49 & -0.58 & 1.06 & 1.59 & 2.37 & 1.99 & 1.22 & 1.45 & 1.09 & 1.08 \\
\hline & 0.28 & 0.43 & 0.62 & 0.63 & 1.08 & 1.17 & 0.44 & 0.37 & 0.94 & 0.62 & 0.36 & 0.66 & 2.05 & 1.69 & 0.58 & 0.77 \\
\hline \multirow[t]{2}{*}{ Overall } & 1.22 & 1.62 & 1.69 & 1.66 & 1.69 & 1.62 & 0.00 & -0.08 & 1.73 & 1.55 & 1.96 & 1.84 & 0.79 & 0.87 & 1.11 & 0.96 \\
\hline & 0.20 & 0.30 & 0.15 & 0.24 & 0.77 & 0.89 & 0.05 & 0.05 & 0.18 & 0.13 & 0.23 & 0.44 & 0.14 & 0.25 & 0.45 & 0.56 \\
\hline \multicolumn{17}{|l|}{$S P Y$} \\
\hline \multirow[t]{2}{*}{ Small } & 2.11 & 2.04 & 2.43 & 2.13 & -0.06 & -0.76 & 0.04 & $-0.17 *$ & 1.75 & 2.01 & 2.16 & 1.96 & 1.23 & 1.00 & 0.96 & 0.65 \\
\hline & 0.13 & 0.11 & 0.33 & 0.26 & 0.50 & 0.61 & 0.09 & 0.07 & 0.35 & 0.28 & 0.29 & 0.26 & 0.36 & 0.25 & 0.19 & 0.17 \\
\hline \multirow[t]{2}{*}{ Medium } & 2.62 & 2.40 & 3.00 & 2.23 & 4.29 & 3.94 & -0.11 & -0.05 & 2.86 & 2.65 & 2.13 & 2.27 & 1.07 & 0.74 & 1.92 & 1.52 \\
\hline & 0.12 & 0.26 & 0.33 & 0.46 & 3.74 & 3.44 & 0.29 & 0.20 & 0.36 & 0.62 & 0.61 & 0.48 & 0.97 & 0.65 & 0.26 & 0.31 \\
\hline \multirow[t]{2}{*}{ Large } & 2.47 & 3.13 & 3.85 & 3.47 & 5.65 & 5.62 & 1.12 & -1.64 & 4.14 & 2.11 & 1.72 & 3.25 & -1.68 & -3.75 & 4.03 & 4.48 \\
\hline & 0.56 & 0.20 & 1.98 & 3.76 & 1.31 & 2.31 & 1.52 & 2.33 & 3.30 & 2.98 & 0.99 & 0.86 & 10.70 & 3.75 & 0.45 & 0.64 \\
\hline \multirow[t]{2}{*}{ Overall } & 2.51 & 2.76 & 2.68 & 2.20 & 4.68 & 4.76 & 0.01 & -0.19 & 2.23 & 2.45 & 1.72 & 2.94 & 0.85 & 0.88 & 3.46 & 3.85 \\
\hline & 0.29 & 0.18 & 0.20 & 0.29 & 1.09 & 1.98 & 0.14 & 0.07 & 0.56 & 0.37 & 0.74 & 0.66 & 0.91 & 0.35 & 0.36 & 0.51 \\
\hline
\end{tabular}

An asterisk $(*)$ represents a statistically significant difference between the pre- and post-period at the 0.05 level.

and thus it seems unwise to read much into this single significant result. ${ }^{9}$ Again, the three-cent rule appears to be a non-event in terms of harming market quality.

The previous tables indicate that trading costs are mostly unaffected by the imposition of the de minimis exemption. If anything, there is modest evidence of lower effective and realized spreads under the 3-cent exemption. However, it is possible that there is some other market-wide effect operating over this same time interval that differs systematically in the pre and post periods. For example, overall stock market levels are somewhat lower in the post period, so the share price of these ETFs is lower (see Table 1). Thus, it might make sense to measure spreads in basis points rather than in cents. Also, we know that spreads are strongly related to volatility, and we know that there is a common factor in liquidity. To account for

\footnotetext{
${ }^{9}$ Recall that Cincinnati trades exclude trades executed on Island and printed on the Cincinnati Stock Exchange.
} 
Table 6

Spread regressions controlling for changes in liquidity

The dependent variable is share-weighted average effective spreads in basis points for one ETF on one day with quote midpoints calculated four different ways, so there are 75 observations in each regression. Post is a dummy variable equal to one during the period of the 3-cent trade-through exemption. The three dummy variables for the ETFs are DIA, QQQ, and SPY. The daily difference between the highest and lowest transaction price in that ETF is volatility. The share-weighted daily average effective spread for all NYSE-listed stocks is market liquidity. $t$-Statistics are in parentheses.

\begin{tabular}{|c|c|c|c|c|c|c|c|c|}
\hline \multirow[t]{2}{*}{ Variable } & \multicolumn{2}{|c|}{ TAQ No cross } & \multicolumn{2}{|l|}{ TAQ } & \multicolumn{2}{|c|}{$\begin{array}{l}\text { TAQ and Island w/2- } \\
\text { second delay No cross }\end{array}$} & \multicolumn{2}{|c|}{$\begin{array}{l}\text { TAQ and Island w/2- } \\
\text { second delay }\end{array}$} \\
\hline & $\begin{array}{l}\text { Effective } \\
\text { spread }\end{array}$ & $\begin{array}{l}\text { Realized } \\
\text { spread }\end{array}$ & $\begin{array}{l}\text { Effective } \\
\text { spread }\end{array}$ & $\begin{array}{l}\text { Realized } \\
\text { spread }\end{array}$ & $\begin{array}{l}\text { Effective } \\
\text { spread }\end{array}$ & $\begin{array}{l}\text { Realized } \\
\text { spread }\end{array}$ & $\begin{array}{l}\text { Effective } \\
\text { spread }\end{array}$ & $\begin{array}{l}\text { Realized } \\
\text { spread }\end{array}$ \\
\hline Post & $\begin{array}{r}-0.19 \\
(0.49)\end{array}$ & $\begin{array}{c}0.14 \\
(0.39)\end{array}$ & $\begin{array}{r}-0.27 \\
(0.71)\end{array}$ & $\begin{array}{c}0.08 \\
(0.22)\end{array}$ & $\begin{array}{r}-0.16 \\
(0.55)\end{array}$ & $\begin{array}{c}0.17 \\
(0.53)\end{array}$ & $\begin{array}{r}-0.20 \\
(1.05)\end{array}$ & $\begin{array}{c}0.01 \\
(0.33)\end{array}$ \\
\hline DIA & $\begin{array}{c}4.30 \\
(1.58)\end{array}$ & $\begin{array}{r}-0.66 \\
(0.26)\end{array}$ & $\begin{array}{c}4.33 \\
(1.69)\end{array}$ & $\begin{array}{r}-0.57 \\
(0.22)\end{array}$ & $\begin{array}{c}0.01 \\
(0.04)\end{array}$ & $\begin{array}{c}2.85 \\
(1.29)\end{array}$ & $\begin{array}{c}1.12 \\
(0.86)\end{array}$ & $\begin{array}{l}3.39 \\
(1.64)\end{array}$ \\
\hline QQQ & $\begin{array}{l}10.88 \\
(3.94)\end{array}$ & $\begin{array}{c}0.73 \\
(0.29)\end{array}$ & $\begin{array}{l}10.65 \\
(4.15)\end{array}$ & $\begin{array}{c}0.75 \\
(0.30)\end{array}$ & $\begin{array}{l}4.50 \\
(2.30)\end{array}$ & $\begin{array}{c}4.02 \\
(1.81)\end{array}$ & $\begin{array}{c}4.37 \\
(3.33)\end{array}$ & $\begin{array}{l}4.62 \\
(2.23)\end{array}$ \\
\hline SPY & $\begin{array}{c}4.15 \\
(1.50)\end{array}$ & $\begin{array}{r}-0.67 \\
(0.27)\end{array}$ & $\begin{array}{c}4.12 \\
(1.61)\end{array}$ & $\begin{array}{r}-0.60 \\
(0.24)\end{array}$ & $\begin{array}{c}0.01 \\
(0.04)\end{array}$ & $\begin{array}{c}2.54 \\
(1.15)\end{array}$ & $\begin{array}{c}0.97 \\
(0.74)\end{array}$ & $\begin{array}{c}3.15 \\
(1.52)\end{array}$ \\
\hline Volatility & $\begin{array}{c}0.44 \\
(1.53)\end{array}$ & $\begin{array}{c}-0.23 \\
(-0.89)\end{array}$ & $\begin{array}{c}0.41 \\
(1.56)\end{array}$ & $\begin{array}{r}-0.28 \\
(1.08)\end{array}$ & $\begin{array}{c}0.29 \\
(1.42)\end{array}$ & $\begin{array}{c}-0.21 \\
(-0.91)\end{array}$ & $\begin{array}{c}0.16 \\
(1.16)\end{array}$ & $\begin{array}{r}-0.29 \\
(1.39)\end{array}$ \\
\hline $\begin{array}{l}\text { Market } \\
\text { liquidity }\end{array}$ & $\begin{array}{r}-0.03 \\
(0.21)\end{array}$ & 0.21 & $\begin{array}{r}-0.03 \\
(0.21)\end{array}$ & 0.21 & 0.19 & 0.01 & $(1.86)$ & $\begin{array}{r}-0.01 \\
(0.06)\end{array}$ \\
\hline
\end{tabular}

this, we include as controls both a volatility measure and a measure of spreads in other stocks. ETF spreads should be positively related to both of these. We use the contemporaneous day's transaction price range (the day's high minus the day's low) in the given ETF as the volatility measure. To measure changes in other stocks' bid-ask spreads, we construct a market-wide liquidity factor based on the dollar volume-weighted daily average effective spread for all NYSE-listed common stocks. Finally, we include a fixed effect for each ETF to capture ETF-specific characteristics. Table 6 regresses average daily ETF percentage effective and realized spreads on ETF dummies, a post-event dummy, volatility, and the market liquidity factor. We calculate spreads using four different quote midpoints: the TAQ NBBO, and an NBBO that merges TAQ and Island quotes, in each case first excluding and then including quotes that cross the market. When we merge in Island quotes, they are delayed by two seconds based on our experience in comparing the ITCH and TAQ timestamps for Island trades.

In Table 6, note that spreads tend to be much lower when Island quotes are included. Other than that, the regressions come to the same conclusions no matter which quote midpoint we use as a reference. To remain consistent with other results in the paper, we focus on the regression results using all TAQ quotes (the second of the four sets of regressions in the table). The ETF dummies demonstrate that while QQQ has the lowest spreads measured in cents, its low share price means it has the 
highest percentage spreads, with an intercept of 10.65 basis points in the pre-event period. There is no evidence that the 3-cent trade-through rule affects either effective or realized spreads. The coefficients on the event dummy are insignificant and very close to zero. For example, the estimated effect of the event on effective half-spreads is a decline of 0.27 basis points, with a t-statistic of only about 0.3. Even after controlling for differences in volatility and market-wide liquidity, there is no evidence that the trade-through rule affects market quality in these ETFs. ${ }^{10}$

An alternative approach to trading cost measurement is to use SEC Rule 11Ac1-5 (Dash5) filings by various market centers. Under Dash5, each market center must report monthly aggregate execution costs (including effective spreads and realized spreads) by stock for market orders and marketable limit orders of less than 10,000 shares. There are two main advantages to Dash5. First, there is no error in inferring whether a given trade was buyer or seller initiated. Second, execution costs are calculated based on the prevailing quotes at the time the order is received at the market center, not at the time the order is executed. However, Dash5 data cannot be used sensibly in this study. Recall that Island goes dark in these three ETFs on September 23, 2002, causing substantial changes in order flow routing and in overall market quality. Thus, the September monthly averages would be confounded by this important subsequent event.

\section{Effects on the efficiency of price discovery}

An important benefit of concentrating trading in a single market is more efficient price discovery (Pagano, 1989). Thus, the de minimis exemption could hamper the incorporation of information into ETF prices if it effectively reduces the degree of linkage between venues. Since trading costs do not increase post-event, one might not expect any effect on price discovery. For completeness, however, we examine the behavior of ETF prices along with their relationship to futures prices.

We begin by looking at how close ETF prices are to a random walk over short horizons. To take out the effects of bid-ask bounce, we examine quote midpoints and measure the autocorrelation of their changes. Table 7 shows the average daily autocorrelation of quote midpoint returns over 15-, 30- and 60-second intervals by ETF for the pre and post periods. As discussed earlier, we use the TAQ NBBO to calculate the quote midpoint, but the results are the same if we merge Island quotes in with the consolidated quote.

The autocorrelations in Table 7 are all positive, signifying lagged adjustment to information at these short horizons. However, there is no systematic change in quote return autocorrelations from the pre period to the post period. There is a slight improvement in the speed of price discovery for QQQ (the 15-second return autocorrelation declines from 0.10 to 0.06 ), and a slight worsening in the speed of

\footnotetext{
${ }^{10}$ The effect of the event is unchanged when we add the inverse of share price to this regression.
} 
Table 7

Quote return autocorrelations

The first order autocorrelation of TAQ quote midpoint returns is calculated over 15-, 30-, and 60-second intervals for each ETF each day and then averaged across days. The pre period is August 16, 2002 to September 3, 2002 and the post period is September 4, 2002 to September 20, 2002. Standard errors are in parentheses.

\begin{tabular}{|c|c|c|c|c|c|c|}
\hline \multirow[t]{2}{*}{ Interval } & \multicolumn{2}{|l|}{ DIA } & \multicolumn{2}{|l|}{ QQQ } & \multicolumn{2}{|l|}{ SPY } \\
\hline & Pre & Post & Pre & Post & Pre & Post \\
\hline 15 seconds & $\begin{array}{c}0.04 \\
(0.02)\end{array}$ & $\begin{array}{c}0.08^{*} \\
(0.01)\end{array}$ & $\begin{array}{c}0.10 \\
(0.01)\end{array}$ & $\begin{array}{c}0.06^{*} \\
(0.01)\end{array}$ & $\begin{array}{c}0.19 \\
(0.01)\end{array}$ & $\begin{array}{c}0.17 \\
(0.01)\end{array}$ \\
\hline 30 seconds & $\begin{array}{c}0.13 \\
(0.01)\end{array}$ & $\begin{array}{c}0.14 \\
(0.01)\end{array}$ & $\begin{array}{c}0.18 \\
(0.01)\end{array}$ & $\begin{array}{c}0.14^{*} \\
(0.01)\end{array}$ & $\begin{array}{c}0.19 \\
(0.01)\end{array}$ & $\begin{array}{c}0.18 \\
(0.02)\end{array}$ \\
\hline 60 seconds & $\begin{array}{c}0.09 \\
(0.02)\end{array}$ & $\begin{array}{c}0.11 \\
(0.02)\end{array}$ & $\begin{array}{c}0.16 \\
(0.02)\end{array}$ & $\begin{array}{c}0.12 * \\
(0.02)\end{array}$ & $\begin{array}{c}0.08 \\
(0.02)\end{array}$ & $\begin{array}{c}0.11 \\
(0.02)\end{array}$ \\
\hline
\end{tabular}

An asterisk $(*)$ represents a statistically significant difference between the pre- and post-period at the 0.05 level.

price discovery for DIA (the 15-second return autocorrelation rises from 0.04 to 0.08). Changes for SPY are all indistinguishable from zero. Autocorrelations over five-minute and longer intervals are not reported, but are very close to zero in both the pre and post periods.

For all three ETFs studied here, there are also futures traded on the same underlying securities. Changes in the ETF market may also affect the linkages between the ETF and futures markets. Hasbrouck (2003) shows that almost all price discovery in the Nasdaq 100 and S\&P 500 futures markets occurs in the E-minis, which are variants of the standard index futures contracts with a smaller contract size and electronic rather than pit trading. To look at price discovery in the ETF and futures markets, we calculate first-order cross-correlations of returns in the two markets. We use E-mini transaction price data and ETF quote midpoints. ${ }^{11}$ If price discovery is fully efficient across the ETF and futures markets, these crosscorrelations should be zero.

Table 8 shows the average daily first-order cross autocorrelation of ETF quote midpoint returns and E-mini futures transaction price returns for 15-, 30-, and 60second intervals. Again, we calculate the ETF quote returns using the CQ NBBO, but the results are the same when we include Island quotes. The crossautocorrelation of ETF NBBO returns with lagged E-mini returns is positive, while the lagged ETF returns provide little predictive power for current E-mini returns. This implies that ETF prices lag futures prices. This is consistent with Hasbrouck

\footnotetext{
${ }^{11}$ Historical quotes for Globex trading are not available from the Chicago Mercantile Exchange, so transaction prices are used. ETF transaction prices provide the same qualitative results, but the bid-ask bounce increases the variance of ETF returns, reducing the autocorrelations toward zero in both the pre and post periods.
} 
Table 8

ETF and futures return cross-autocorrelations

First-order cross-autocorrelation of ETF quote midpoint returns from TAQ and E-mini future transaction price returns from the CME, calculated for each index each day and then averaged across days. The pre period is August 16, 2002 to September 3, 2002 and the post period is September 4, 2002 to September 20, 2002. Standard errors are in parentheses.

\begin{tabular}{|c|c|c|c|c|}
\hline \multirow[t]{2}{*}{ Interval } & \multicolumn{2}{|c|}{ Nasdaq-100 } & \multicolumn{2}{|c|}{ S\&P 500} \\
\hline & Pre & Post & Pre & Post \\
\hline \multicolumn{5}{|c|}{ Correlation between ETF and lag 1 E-mini } \\
\hline 15 seconds & $\begin{array}{c}0.40 \\
(0.02)\end{array}$ & $\begin{array}{c}0.30^{*} \\
(0.03)\end{array}$ & $\begin{array}{c}0.40 \\
(0.02)\end{array}$ & $\begin{array}{c}0.39 \\
(0.01)\end{array}$ \\
\hline 30 seconds & $\begin{array}{c}0.49 \\
(0.01)\end{array}$ & $\begin{array}{c}0.40^{*} \\
(0.03)\end{array}$ & $\begin{array}{c}0.38 \\
(0.03)\end{array}$ & $\begin{array}{c}0.38 \\
(0.01)\end{array}$ \\
\hline 60 seconds & $\begin{array}{c}0.40 \\
(0.02)\end{array}$ & $\begin{array}{c}0.30^{*} \\
(0.02)\end{array}$ & $\begin{array}{c}0.22 \\
(0.01)\end{array}$ & $\begin{array}{c}0.25 \\
(0.02)\end{array}$ \\
\hline \multicolumn{5}{|c|}{ Correlation between E-mini and lag 1 ETF } \\
\hline 15 seconds & $\begin{array}{c}-0.01 \\
(0.01)\end{array}$ & $\begin{array}{r}-0.01 \\
(0.01)\end{array}$ & $\begin{array}{c}0.05 \\
(0.01)\end{array}$ & $\begin{array}{c}0.03 * \\
(0.01)\end{array}$ \\
\hline 30 seconds & $\begin{array}{r}-0.01 \\
(0.02)\end{array}$ & $\begin{array}{r}-0.03 \\
(0.01)\end{array}$ & $\begin{array}{c}0.02 \\
(0.02)\end{array}$ & $\begin{array}{c}0.02 \\
(0.01)\end{array}$ \\
\hline 60 seconds & $\begin{array}{r}-0.03 \\
(0.02)\end{array}$ & $\begin{array}{r}-0.01 \\
(0.02)\end{array}$ & $\begin{array}{r}-0.03 \\
(0.02)\end{array}$ & $\begin{array}{r}-0.02 \\
(0.02)\end{array}$ \\
\hline
\end{tabular}

An asterisk $(*)$ represents a statistically significant difference between the pre- and post-periods at the 0.05 level.

(2003), who finds that price discovery in these indexes is concentrated in the E-mini futures market. ${ }^{12}$ When the trade-through exemption takes effect, ETF prices actually catch up to the futures a bit more quickly, at least for the Nasdaq-100. For example, the cross-autocorrelation in 15-second Nasdaq-100 returns goes from 0.40 pre- to 0.30 post-event.

Thus, the evidence based on quote autocorrelations and return crossautocorrelations is quite mixed. When the trade-through exemption goes into effect, some tests indicate that prices become slightly more efficient, and some tests indicate that prices become slightly less efficient. Some tests find no evidence of a change in efficiency, and that is probably the best way to interpret the overall evidence.

\footnotetext{
${ }^{12}$ This could also be due to difficulties in reconciling the times across both markets. The discussion of merging the TAQ and ITCH data notes the several second lags between the ITCH time stamps and the TAQ time stamps. The changes between the pre- and post-dark periods in the cross auto-correlations here are not sensitive to this - similar results are found when ETF returns are calculated using ETF transaction prices and when ETF returns are calculated using Island transaction prices with the ITCH time stamps, but the magnitude of the futures lead over ETF prices is sensitive to these timing issues.
} 


\section{Explanations}

Why does the three-cent trade-through exemption have so little impact on market quality? Conversations with market participants indicate that trade-throughs occurred frequently in these ETFs prior to September 4, 2002. Prices often moved rapidly, and at the same time spreads were quite narrow. This resulted in many trade-throughs, both intentional and unintentional. Intentional trade-throughs were not necessarily the fault of the market-maker. At the time, some fraction of the trading volume in these ETFs involved arbitrage with the corresponding futures, and such arbitrageurs probably valued execution certainty enough to trade at inferior prices on an automated venue. In fact, some have interpreted the de minimis exemption as an admission by the SEC that strict trade-through prohibitions had become difficult if not impossible to enforce in these particular markets. Thus, it is possible that the de minimis exemption has little effect on the practice of trading through in these ETFs. This would account for the minimal effect of the rule change on market quality.

To investigate this possibility, we look at the incidence of trade-throughs before and after the event. Using TAQ data and timestamps, we compare execution prices to the regulatory $\mathrm{NBBO}$ (excluding quotes less than or equal to 100 shares) prevailing at the time of the trade. If the trade is less than 10,000 shares, we assume it is subject to the trade-through prohibitions, and we measure whether there is a tradethrough and the extent of the trade-through in cents. ${ }^{13}$

The discussion continues to focus on small trades of at most 1,000 shares. Among other reasons, these trades are most likely to be standard trade types that would be subject to the trade-through rules. The left half of Table 9 shows that trade-throughs are common in these ETFs. About one-third of small trades trade through the posted quote at the time of the trade print. Even more surprising, however, is that the overall trade-through rate for small trades does not change at all once the de minimis exemption goes into effect. The trade-through rate is $32 \%$ for DIA before and after, 37\% for QQQ before and after, and 35\% for SPY before and after the new rule. One would expect an increase if the trade-through rule is at all binding, but there is no evidence of such an increase.

Some of these trade-throughs could be unintentional, the result of lags in executing and printing trades. That is, better prices were not available elsewhere at the time the order was executed, but better prices became available in the time it took for the trade to appear on the consolidated tape, which is typically one to two seconds after submission. To investigate this, we look back at all NBBOs for the 10 seconds prior to the trade print, and only executions that take place outside all NBBOs during this interval are counted as trade-throughs. ${ }^{14}$ This means we are looking for any possible quote in this interval that might justify the reported trade.

\footnotetext{
${ }^{13}$ Some order types are not subject to the trade-through rule, and there are special rules that apply to a venue that locks or crosses the market. Because order types are not observable in the TAQ data, we assume that all trades of less than 10,000 shares are in fact subject to the rule.

${ }^{14} \mathrm{We}$ thank Bruce Lehmann, the editor, for suggesting this.
} 
Table 9

Overall trade-through rates

The fraction of executions that trade through the TAQ NBBO at the time of the trade print (left half of the table), and the fraction that are outside all NBBOs 0-10 seconds before the trade print (right half). Trade-through rates are calculated for each ETF each day and then averaged across days. The pre period is August 16, 2002 to September 3, 2002 and the post period is September 4, 2002 to September 20, 2002. Small trades are 100 to 1,000 shares; medium trades are 1,001 to 9,999 shares. Standard errors are in parentheses.

\begin{tabular}{|c|c|c|c|c|c|c|c|c|c|c|c|c|}
\hline \multirow[t]{3}{*}{ Trade size } & \multicolumn{6}{|c|}{$\begin{array}{l}\text { Based on TAQ NBBO at time of trade } \\
\text { print }\end{array}$} & \multicolumn{6}{|c|}{$\begin{array}{l}\text { Based on all NBBOs } 0-10 \text { seconds before } \\
\text { print }\end{array}$} \\
\hline & \multicolumn{2}{|l|}{ DIA } & \multicolumn{2}{|l|}{ QQQ } & \multicolumn{2}{|l|}{ SPY } & \multicolumn{2}{|l|}{ DIA } & \multicolumn{2}{|l|}{ QQQ } & \multicolumn{2}{|l|}{ SPY } \\
\hline & Pre & Post & Pre & Post & Pre & Post & Pre & Post & Pre & Post & Pre & Post \\
\hline \multicolumn{13}{|c|}{ Trade-throughs of any amount } \\
\hline Small & $\begin{array}{c}0.32 \\
(0.01)\end{array}$ & $\begin{array}{c}0.32 \\
(0.01)\end{array}$ & $\begin{array}{c}0.37 \\
(0.01)\end{array}$ & $\begin{array}{c}0.37 \\
(0.01)\end{array}$ & $\begin{array}{c}0.35 \\
(0.01)\end{array}$ & $\begin{array}{c}0.35 \\
(0.01)\end{array}$ & $\begin{array}{c}0.26 \\
(0.01)\end{array}$ & $\begin{array}{c}0.26 \\
(0.01)\end{array}$ & $\begin{array}{c}0.33 \\
(0.01)\end{array}$ & $\begin{array}{c}0.32 \\
(0.01)\end{array}$ & $\begin{array}{c}0.29 \\
(0.01)\end{array}$ & $\begin{array}{c}0.29 \\
(0.01)\end{array}$ \\
\hline Medium & $\begin{array}{c}0.41 \\
(0.01)\end{array}$ & $\begin{array}{l}0.41 \\
(0.01)\end{array}$ & $\begin{array}{c}0.41 \\
(0.01)\end{array}$ & $\begin{array}{r}0.40^{*} \\
(0.01)\end{array}$ & $\begin{array}{c}0.43 \\
(0.01)\end{array}$ & $\begin{array}{r}0.41^{*} \\
(0.01)\end{array}$ & $\begin{array}{c}0.34 \\
(0.01)\end{array}$ & $\begin{array}{c}0.34 \\
(0.01)\end{array}$ & $\begin{array}{c}0.36 \\
(0.01)\end{array}$ & $\begin{array}{c}0.35^{*} \\
(0.01)\end{array}$ & $\begin{array}{c}0.35 \\
(0.01)\end{array}$ & $\begin{array}{c}0.33^{*} \\
(0.01)\end{array}$ \\
\hline \multicolumn{13}{|c|}{ Trade-throughs of more than 3 cents } \\
\hline Small & $\begin{array}{c}0.09 \\
(0.01)\end{array}$ & $\begin{array}{c}0.08^{*} \\
(0.01)\end{array}$ & $\begin{array}{c}0.03 \\
(0.00)\end{array}$ & $\begin{array}{c}0.02 * \\
(0.00)\end{array}$ & $\begin{array}{c}0.10 \\
(0.01)\end{array}$ & $\begin{array}{c}0.09 \\
(0.01)\end{array}$ & $\begin{array}{c}0.08 \\
(0.01)\end{array}$ & $\begin{array}{c}0.07 * \\
(0.01)\end{array}$ & $\begin{array}{c}0.02 \\
(0.00)\end{array}$ & $\begin{array}{c}0.02 \\
(0.00)\end{array}$ & $\begin{array}{c}0.08 \\
(0.01)\end{array}$ & $\begin{array}{c}0.08 \\
(0.01)\end{array}$ \\
\hline Medium & $\begin{array}{c}0.18 \\
(0.01)\end{array}$ & $\begin{array}{c}0.16^{*} \\
(0.01)\end{array}$ & $\begin{array}{c}0.03 \\
(0.00)\end{array}$ & $\begin{array}{c}0.02 \\
(0.00)\end{array}$ & $\begin{array}{c}0.14 \\
(0.01)\end{array}$ & $\begin{array}{c}0.12^{*} \\
(0.01)\end{array}$ & $\begin{array}{c}0.15 \\
(0.01)\end{array}$ & $\begin{array}{c}0.13^{*} \\
(0.01)\end{array}$ & $\begin{array}{c}0.02 \\
(0.00)\end{array}$ & $\begin{array}{c}0.02 \\
(0.00)\end{array}$ & $\begin{array}{c}0.11 \\
(0.01)\end{array}$ & $\begin{array}{c}0.09 * \\
(0.01)\end{array}$ \\
\hline
\end{tabular}

An asterisk $(*)$ represents a statistically significant difference between the pre- and post-period at the 0.05 level.

Assuming that all trades are printed within 10 seconds of their execution, this conservative method should yield a lower bound on the trade-through rate.

The results are in the right half of Table 9. Surprisingly, the trade-through rates are not much lower when we look back 10 seconds. For example, SPY trade-through rates for small trades are $29 \%$ when we look back 10 seconds vs. $35 \%$ using the quote at the time of the print. There are similar proportional declines for all three ETFs, both before and after the trade-through exemption. Thus, the observed high trade-through rates cannot be explained away by reporting lags. ${ }^{15}$

We also calculate the fraction of trades that trade through the posted quote by more than 3 cents. These trades remain prohibited both before and after the de minimis exemption. These trade-throughs occur less frequently, but still occur almost $10 \%$ of the time in DIA and SPY $(8 \%$ of the time if we look back 10 seconds for any quote that would justify the trade). Trade-throughs of this magnitude are much less common in QQQ, most likely because the QQQ share price is much lower than that of the other two ETFs. Interestingly, these trade-throughs become slightly

\footnotetext{
${ }^{15}$ Increasing the lag beyond 10 seconds further reduces the frequency of trade-throughs, but even at a lag of 90 seconds, trade-through rates on small orders are still between $18 \%$ and $24 \%$.
} 
less frequent after the de minimis exemption. For example, trade-throughs of more than 3 cents occur in DIA $9 \%$ of the time pre-event and $8 \%$ afterward. QQQ and SPY rates also fall by about one percentage point. This decline may seem counterintuitive, but a reduction here makes sense if the trade-through restrictions are essentially unenforced pre-event, and market participants believe that the de minimis exemption makes enforcement possible again for bigger trade-throughs.

Next we look at trade-throughs venue by venue, for the same reasons as before. Are there market centers that take advantage of the relaxed rules and trade through more often? We might expect no effect on Island and ARCA, the identifiable automated venues, and more of an effect on venues dominated by a market-maker with incentives to maximize trading profit subject to a trade-through constraint. Again we focus on small trades of at most 1,000 shares, which are more likely to be retail and might be less able to evaluate and thus limit such market-maker behavior.

Table 10 has the very interesting results. Once the de minimis exemption is in place, AMEX trades through the quote more often in all three ETFs. The increase in trade-through frequency is modest, from 2 to 4 percentage points, but it is statistically significant. Other non-automated exchanges with designated marketmakers or specialists also trade through more often. Boston trades through more

Table 10

Trade-through rates by venue

The fraction of executions that trade through the posted NBBO from TAQ, calculated for each ETF each day and then averaged across days. The pre period is August 16, 2002 to September 3, 2002 and the post period is September 4, 2002 to September 20, 2002. Small trades are 100 to 1,000 shares; medium trades are 1,001 to 9,999 shares. Standard errors are immediately beneath the trade-through fractions.

\begin{tabular}{|c|c|c|c|c|c|c|c|c|c|c|c|c|c|c|c|c|}
\hline \multirow[t]{2}{*}{ Trade size } & \multicolumn{2}{|c|}{ AMEX } & \multicolumn{2}{|c|}{ Boston } & \multicolumn{2}{|c|}{ Cinn } & \multicolumn{2}{|c|}{ Island } & \multicolumn{2}{|c|}{ Midwest } & \multicolumn{2}{|c|}{ NYSE } & \multicolumn{2}{|c|}{ ARCA-P } & \multicolumn{2}{|c|}{ Instinet-3rd } \\
\hline & Pre & Post & Pre & Post & Pre & Post & Pre & Post & Pre & Post & Pre & Post & Pre & Post & Pre & Post \\
\hline \multicolumn{17}{|l|}{$D I A$} \\
\hline \multirow[t]{2}{*}{ Small } & 0.39 & $0.43^{*}$ & 0.30 & $0.34 *$ & 0.15 & 0.16 & 0.35 & 0.34 & 0.29 & 0.26 & 0.40 & $0.47 *$ & 0.13 & 0.12 & 0.26 & 0.27 \\
\hline & 0.01 & 0.01 & 0.01 & 0.03 & 0.01 & 0.01 & 0.01 & 0.01 & 0.02 & 0.02 & 0.02 & 0.02 & 0.01 & 0.01 & 0.01 & 0.01 \\
\hline \multirow[t]{2}{*}{ Medium } & 0.45 & 0.46 & 0.47 & 0.47 & 0.46 & 0.46 & 0.33 & 0.31 & 0.39 & 0.37 & 0.46 & $0.53^{*}$ & 0.15 & 0.13 & 0.45 & 0.43 \\
\hline & 0.01 & 0.02 & 0.03 & 0.04 & 0.04 & 0.05 & 0.02 & 0.02 & 0.03 & 0.03 & 0.02 & 0.03 & 0.08 & 0.02 & 0.03 & 0.03 \\
\hline \multicolumn{17}{|l|}{$Q Q Q$} \\
\hline \multirow[t]{2}{*}{ Small } & 0.29 & $0.31 *$ & 0.23 & 0.24 & 0.11 & 0.10 & 0.45 & 0.43 & 0.28 & $0.26^{*}$ & 0.30 & $0.37 *$ & 0.09 & $0.11^{*}$ & 0.33 & $0.30 *$ \\
\hline & 0.01 & 0.01 & 0.01 & 0.01 & 0.01 & 0.01 & 0.01 & 0.01 & 0.01 & 0.01 & 0.01 & 0.01 & 0.01 & 0.00 & 0.01 & 0.01 \\
\hline \multirow[t]{2}{*}{ Medium } & 0.34 & 0.35 & 0.30 & $0.34 *$ & 0.13 & $0.15^{*}$ & 0.45 & $0.42 *$ & 0.46 & 0.46 & 0.34 & $0.40 *$ & 0.10 & $0.12 *$ & 0.39 & $0.34 *$ \\
\hline & 0.01 & 0.01 & 0.01 & 0.01 & 0.01 & 0.02 & 0.01 & 0.01 & 0.01 & 0.01 & 0.01 & 0.01 & 0.01 & 0.01 & 0.01 & 0.01 \\
\hline \multicolumn{17}{|l|}{$S P Y$} \\
\hline \multirow[t]{2}{*}{ Small } & 0.37 & $0.39 *$ & 0.35 & 0.35 & 0.08 & 0.09 & 0.38 & 0.37 & 0.30 & 0.27 & 0.39 & 0.41 & 0.15 & 0.14 & 0.32 & 0.31 \\
\hline & 0.01 & 0.01 & 0.01 & 0.02 & 0.01 & 0.01 & 0.01 & 0.01 & 0.02 & 0.02 & 0.01 & 0.01 & 0.01 & 0.01 & 0.02 & 0.01 \\
\hline \multirow[t]{2}{*}{ Medium } & 0.44 & 0.44 & 0.42 & 0.40 & 0.30 & 0.16 & 0.45 & $0.43^{*}$ & 0.38 & 0.37 & 0.48 & 0.46 & 0.21 & 0.21 & 0.42 & $0.38 *$ \\
\hline & 0.01 & 0.01 & 0.01 & 0.02 & 0.12 & 0.07 & 0.01 & 0.01 & 0.01 & 0.02 & 0.01 & 0.02 & 0.02 & 0.01 & 0.01 & 0.02 \\
\hline
\end{tabular}

An asterisk $(*)$ represents a statistically significant difference between the pre- and post-period at the 0.05 level. 
often in DIA, the Midwest trades through less in QQQ, and the NYSE trades through more often in DIA and QQQ. However, even though these changes in tradethrough rates are statistically different from zero, the trade-through rates do not vary by more than a few percentage points, and recall from Table 9 that in aggregate the trade-through rates do not change at all post-event.

Finally, we look by venue at prints that trade through by more than three cents. The overall evidence indicates that these trade-throughs become less likely, but it is useful to determine whether this decline is concentrated on any subset of venues. Again, it seems unlikely that there would be much of an effect on the automated markets, especially Island, which remains outside the ITS system throughout. It seems more likely ex ante that this exercise might identify market-makers becoming more reluctant to trade through by more than $\$ 0.03$ per share in the presence of potentially increased enforcement by either the SEC or other ITS members.

The results are contained in Table 11. Interestingly, the evidence in Table 11 indicates that the automated markets-including Archipelago and especially Island-are driving the overall decline in trade-throughs exceeding three cents. Island's incidence of trade-throughs greater than three cents declines from $9 \%$ to $7 \%$ in DIA, $3 \%$ to $2 \%$ in QQQ, and $11 \%$ to $9 \%$ in SPY. Since Island does not

Table 11

Trade-throughs exceeding 3 cents, by venue

The fraction of executions that trade through the posted NBBO from TAQ by more than three cents, calculated for each ETF each day and then averaged across days. The pre period is August 16, 2002 to September 3, 2002 and the post period is September 4, 2002 to September 20, 2002. Small trades are 100 to 1,000 shares; medium trades are 1,001 to 9,999 shares. Standard errors are immediately beneath the trade-through fractions.

\begin{tabular}{|c|c|c|c|c|c|c|c|c|c|c|c|c|c|c|c|c|}
\hline \multirow[t]{2}{*}{ Trade size } & \multicolumn{2}{|c|}{ AMEX } & \multicolumn{2}{|c|}{ Boston } & \multicolumn{2}{|c|}{ Cinn } & \multicolumn{2}{|c|}{ Island } & \multicolumn{2}{|c|}{ Midwest } & \multicolumn{2}{|c|}{ NYSE } & \multicolumn{2}{|c|}{ ARCA-P } & \multicolumn{2}{|c|}{ Instinet-3rd } \\
\hline & Pre & Post & Pre & Post & Pre & Post & Pre & Post & Pre & Post & Pre & Post & Pre & Post & Pre & Post \\
\hline \multicolumn{17}{|l|}{$D I A$} \\
\hline \multirow[t]{2}{*}{ Small } & 0.17 & 0.17 & 0.13 & 0.15 & 0.04 & 0.04 & 0.09 & $0.07 *$ & 0.11 & 0.09 & 0.15 & 0.16 & 0.02 & $0.01^{*}$ & 0.07 & 0.07 \\
\hline & 0.01 & 0.01 & 0.01 & 0.02 & 0.00 & 0.00 & 0.01 & 0.01 & 0.02 & 0.02 & 0.01 & 0.01 & 0.00 & 0.00 & 0.01 & 0.01 \\
\hline \multirow[t]{2}{*}{ Medium } & 0.24 & 0.22 & 0.28 & 0.33 & 0.28 & 0.23 & 0.08 & 0.06 & 0.17 & 0.13 & 0.21 & 0.23 & 0.01 & 0.02 & 0.21 & $0.16^{*}$ \\
\hline & 0.01 & 0.01 & 0.03 & 0.05 & 0.03 & 0.05 & 0.01 & 0.01 & 0.02 & 0.03 & 0.02 & 0.02 & 0.01 & 0.01 & 0.02 & 0.02 \\
\hline \multicolumn{17}{|l|}{$Q Q Q$} \\
\hline \multirow[t]{2}{*}{ Small } & 0.00 & $0.01 *$ & 0.01 & 0.01 & 0.01 & 0.00 & 0.03 & $0.02 *$ & 0.02 & 0.02 & 0.01 & 0.01 & 0.00 & 0.00 & 0.03 & $0.02 *$ \\
\hline & 0.00 & 0.00 & 0.00 & 0.00 & 0.00 & 0.00 & 0.01 & 0.00 & 0.00 & 0.00 & 0.00 & 0.00 & 0.00 & 0.00 & 0.00 & 0.00 \\
\hline \multirow[t]{2}{*}{ Medium } & 0.01 & $0.01 *$ & 0.02 & 0.02 & 0.01 & 0.01 & 0.03 & 0.03 & 0.03 & 0.04 & 0.02 & 0.02 & 0.00 & 0.00 & 0.03 & 0.02 \\
\hline & 0.00 & 0.00 & 0.00 & 0.01 & 0.00 & 0.00 & 0.01 & 0.00 & 0.00 & 0.00 & 0.00 & 0.00 & 0.00 & 0.00 & 0.00 & 0.01 \\
\hline \multicolumn{17}{|l|}{$S P Y$} \\
\hline \multirow[t]{2}{*}{ Small } & 0.09 & 0.08 & 0.10 & 0.11 & 0.00 & 0.00 & 0.11 & 0.09 & 0.07 & $0.10^{*}$ & 0.08 & 0.07 & 0.02 & $0.01^{*}$ & 0.09 & 0.09 \\
\hline & 0.01 & 0.01 & 0.01 & 0.02 & 0.00 & 0.00 & 0.01 & 0.01 & 0.01 & 0.01 & 0.01 & 0.01 & 0.01 & 0.00 & 0.01 & 0.02 \\
\hline \multirow[t]{2}{*}{ Medium } & 0.15 & 0.13 & 0.13 & 0.12 & 0.05 & 0.01 & 0.15 & $0.12^{*}$ & 0.10 & 0.10 & 0.15 & $0.11^{*}$ & 0.02 & $0.01^{*}$ & 0.12 & 0.11 \\
\hline & 0.01 & 0.01 & 0.01 & 0.02 & 0.05 & 0.01 & 0.01 & 0.01 & 0.01 & 0.01 & 0.01 & 0.01 & 0.01 & 0.00 & 0.01 & 0.02 \\
\hline
\end{tabular}

An asterisk $(*)$ represents a statistically significant difference between the pre- and post-period at the 0.05 level. 
participate in ITS pre or post-event, either Island markets become tighter, making a three-cent trade-through less likely, or liquidity demanders become less likely to trade through the quote this far, perhaps out of concern about increased enforcement. Based on the evidence in Table 3, Island's effective spreads are lower post-event, suggesting but not proving that tighter markets can explain Island's lower trade-through rate in the post period. In any case, market-makers at the various exchanges do not seem to change their behavior much with respect to trades that are further through the quote.

Overall, there are a surprisingly large number of trade-throughs in these ETFs (30\% to $40 \%$ of all trades), and a surprising number of trades that are more than three cents worse than the posted quote (on the order of $10 \%$ for the two higherpriced ETFs, DIA and SPY). Most surprising is that relaxing the trade-through rule does not result in more trade-throughs. As discussed earlier, this is probably due to the dysfunctional state of the ITS linkage in these stocks prior to the de minimis exemption.

\section{Conclusions}

On September 4, 2002, the SEC implemented a de minimis exemption to the socalled trade-through rule for the three most actively traded ETFs, allowing markets to execute trades at prices up to three cents worse than those posted at other venues. We examine the effects of this regulatory experiment on ETF market quality. There is no evidence that relaxing the trade-through rule worsens market quality. Effective and realized spreads are essentially unchanged or slightly lower after the exemption goes into effect, and there are no identifiable market centers that appear to be using the exemption as an opportunity to gouge customers. ETF prices become slightly more efficient post-event, measured using 15- to 60-second quote return autocorrelations and cross-autocorrelations with futures price innovations.

A look at the frequency of trade-throughs provides part of the explanation: the new rule has almost no effect on the likelihood of trading through. In these ETFs, we establish that the various markets are already trading through with abandon, so the exemption simply represents a case of the rules catching up to practice. The threecent trade-through exemption is close to a non-event for these ETFs.

Among other things, this highlights the importance of enforcement. If tradethrough rules are not enforced, there is little point to having them on the books. The current ITS system requires the aggrieved party to contact the offending market center to obtain restitution. As a result, small trade-throughs are not worth pursuing in practice, and the lack of sanctions reduces venues' incentives to comply with the prohibitions. Furthermore, the evidence here suggests that accurately identifying trade-throughs may be difficult given current data. Thus, we would advise the SEC and other regulators to consider not just the trade-through rules themselves but also their enforcement implications.

The de minimis exemption initially appears to be a useful regulatory experiment, but ultimately this event cannot tell us much about the costs or benefits of a 
trade-through prohibition in other stocks. The previous lack of compliance makes it difficult to extrapolate. From this event, we can conclude only that if the tradethrough rule is already being ignored, a trade-through exemption is unlikely to have much effect. In the current regulatory debate over the proposed Regulation NMS, some are trying to use the ETF de minimis exemption as evidence that trade-through rules have no effect on market quality. Our paper cautions against that kind of conclusion and urges restraint in interpreting the results of this regulatory change.

Compared to most individual equities, these ETFs are extremely actively traded and have very narrow spreads, and pricing is driven by arbitrage considerations. Thus, it seems likely that trade-through rules are ignored more in these ETFs than they are in individual equities. If true, then individual equities may respond very differently to a change in the trade-through rules. Thus, a second regulatory pilot targeting a cross-section of individual common stocks would provide important data points to policymakers.

In principle, trade-through rules could facilitate virtual integration of trading across markets and reduce agency problems between brokers and customers by forcing brokers to find the best price. Therefore, prohibiting trade-throughs and enforcing market integration and linkages by public regulations is sensible if market linkages perform adequately and are well monitored. However, Stoll (2001) compellingly argues that integration can be performed at the investor level by existing sophisticated order-routing software and that mandated regulatory linkages suffer from underinvestment and technological obsolescence. In fact, regulatory linkages such as ITS and the current options linkage are lightly used for just this reason. Thus, prohibiting trade-throughs without solving the technological and incentive problems could stifle innovation by forcing markets to adapt to antiquated public market linkages.

As currently proposed, Regulation NMS partially addresses these concerns by limiting trade-through protection to markets with fast turnaround times, while slower markets can be traded through by at most five cents per share. However, definitions of fast and slow markets will surely prove contentious, as will discussions about the details of the linkages. The SEC proposal also allows investors to opt out of trade-through protection, which may provide flexibility for investors able to monitor effectively the performance of intermediaries. Trade-through rules are also proposed for Nasdaq for the first time. Does this proposal help further a competitive national market system? Even the authors do not completely agree on the answer. We do agree, however, that the national market system could change markedly on the basis of very little empirical data, and we would encourage additional empirical work in this area that would help inform the debate.

\section{References}

Barclay, M.J., et al., 1999. The effects of market reform on the trading costs and depths of Nasdaq stocks. Journal of Finance 54, 1-34.

Barclay, M.J., Hendershott, T., McCormick, D.T., 2003. Competition among trading venues: information and trading on electronic communications networks. Journal of Finance 58, 2637-2666. 
Battalio, R.H., 1997. Third market broker-dealers: cost competitors or cream-skimmers? Journal of Finance 52, 341-352.

Battalio, R., Greene, J., Jennings, R., 1997. Do competing specialists and preferencing dealers affect market quality? Review of Financial Studies 10, 969-993.

Battalio, R., Hatch, B., Jennings, R., 2004. Toward a national market system for U.S. exchange-listed equity options. Journal of Finance 59, 933-962.

Bessembinder, H., 2003. Quote-based competition and trade execution costs in NYSE-listed stocks. Journal of Financial Economics 70, 385-422.

Bessembinder, H., Kaufman, H.M., 1997. A cross-exchange comparison of execution costs and information flow for NYSE-listed stocks. Journal of Financial Economics 46, 293-319.

Bloomfield, R., O’Hara, M., 1998. Does order preferencing matter? Journal of Financial Economics 50, $3-37$.

Chung, K.H., Chuwonganant, C., McCormick, D.T., 2004. Order preferencing and market quality on NASDAQ before and after decimalization. Journal of Financial Economics 71, 581-612.

de Fontnouvelle, P., Fishe, R.P.H., Harris, J.H., 2003. The behavior of bid-ask spreads and volume in options markets during the competition for listings in 1999. Journal of Finance 58, 2437-2463.

Easley, D., Kiefer, N.M., O’Hara, M., 1996. Cream-skimming or profit-sharing? The curious role of purchased order flow. Journal of Finance 51, 811-833.

Hasbrouck, J., 2003. Intraday price formation in the U.S. equity index markets. Journal of Finance 58, 2375-2400.

Hasbrouck, J., Sofianos, G., Sosebee, D., 1993. New York Stock Exchange systems and trading procedures. NYSE Working Paper \#93-01.

Hendershott, T., Jones, C.M., 2004. Island goes dark: transparency, fragmentation, and regulation. Review of Financial Studies, forthcoming.

Lee, C.M.C., Ready, M.J., 1991. Inferring trade direction from intraday data. Journal of Finance 46, 733-747.

Macey, J.R., O'Hara, M., 1997. The law and economics of best execution. Journal of Financial Intermediation 6, 188-223.

O'Hara, M., 2004. Searching for a new center: U.S. securities markets in transition. Working paper, Cornell University.

Pagano, M., 1989. Endogenous market thinness and stock price volatility. Review of Economic Studies 56, 269-287.

Parlour, C.A., Rajan, U., 2003. Payment for order flow. Journal of Financial Economics 68, $379-411$.

Stoll, H.R., 2001. Market fragmentation. Financial Analysts Journal 57, 16-20. 